\section{Right superior vena cava draining into the left atrium with left superior vena cava draining into the right atrium}

Patients with a right to left shunt frequently present with brain abscesses because any organism carried in the venous blood may shunt the physiological lung filter and be carried in the systemic circulation. ${ }^{1}$ In a patient with a brain abscess we found a congenital type of right to left shunt that has not been reported.

\section{Case report}

A 44 year old healthy man presented with a large parietal brain abscess. He had a two week history of fever, headache, and nausea, and a left lateral homonymous hemianopia with bilateral papilloedema was found. A puncture yielded $15 \mathrm{~cm}^{3}$ of pus from the abscess, and three months of treatment with ceftriaxone ( $3 \mathrm{~g}$ daily by a single intravenous bolus) was started. Neurological examination and computed tomography yielded normal results within 15 days and three months, respectively. No causative organism was isolated.

Clinical examination of the chest, echocardiography, chest radiography, and tests of immunological and renal functions yielded normal results. Although this patient's physical activities had been normal, he had mild digital clubbing and mild hypoxia $(85 \mathrm{~mm} \mathrm{Hg}$ ) but no cyanosis. Before treatment with antibiotics was stopped he underwent pulmonary angiography. A catheter, introduced through the cubital vein of the right arm, was pushed into a small right superior vena cava draining into the left atrium and receiving blood from the right subclavian and jugular veins. Another catheter was introduced through the right femoral vein and pushed gradually into the inferior vena cava, the right atrium, and finally a left superior vena cava draining into the right atrium and receiving blood from left subclavian and jugular veins. There was no anomalous pulmonary blood return or an intracardiac shunt. When a small balloon was inflated into the lower part of the right superior vena cava, just above the left atrium, blood pressure did not

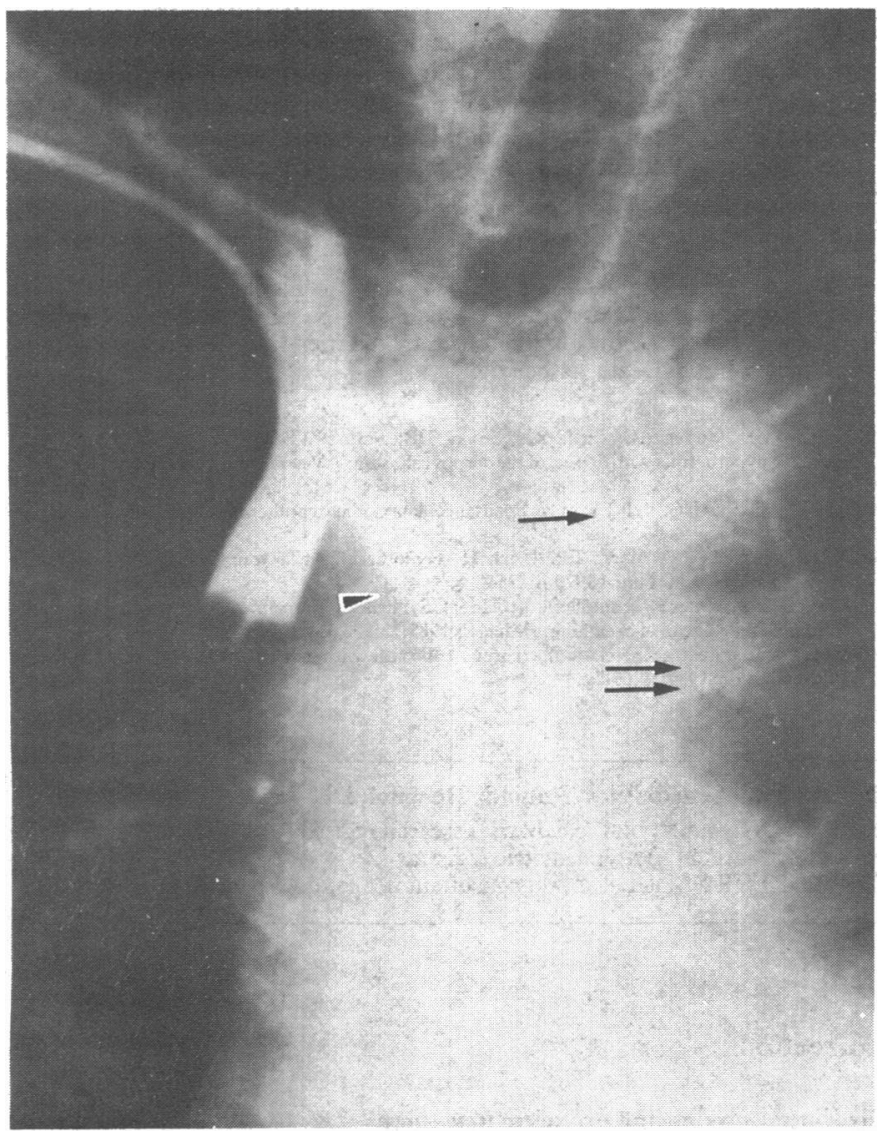

Posteroanterior frame from cineangiocardiography performed in the right superior vena cava. When the blood flow was stopped in the right superior vena cava by a balloon blood went through the anastomosis (single arrow) to the left superior vena cava (double arrow) and the azygos vena (arrow head). increase above and blood passed through an anastomosis to the left superior vena cava and the azygos vena, both draining into the right cavities (figure). The right superior vena cava was ligatured successfully just above the left atrium. No relapse had been reported six months later.

\section{Comment}

We have found no report of a similar anomaly; however, other malformations in the superior vena cava have been reported, usually as a persistent left superior vena cava. A left superior vena cava draining into the left atrium and causing a right to left shunt with cyanosis usually coexists with other cardiac anomalies ${ }^{\prime}$; a persistent left superior vena cava draining into the right atrium is a frequent type of malformation, usually associated with a normal right superior vena cava, and does not cause any haemodynamic change. ${ }^{2}$

A right superior vena cava draining into the left atrium is even rarer. The three reported cases most similar to ours were nevertheless quite different from ours because of clinical evidence of cyanosis during childhood and the absence of brain abscesses in two. ${ }^{3-5}$ In the third case the diagnosis had been made after recurrent brain abscesses, but cyanosis was also evident. In all three cases the right superior vena cava was an isolated anomaly without a persistent left superior vena cava. Our patient's good tolerance and the absence of cyanosis probably resulted from the persistence of a left superior vena cava, normally draining into the right cavities, and the anastomosis, which decreased the shunt flow.

1 Dupuis C, Pernot C, Rey C, Worms AM, Marcon F, Vancostenoble JF. La veine cave supérieure gauche communicant avec l'oreillette gauche. A propos de huit observations. Arch Mal Coeur gauche communican $1981 ; 11: 507-16$.

2 Cha EM, Khoury GH. Persistent left superior vena cava. Radiological and clinical significance. Radiology 1972;103:375-81.

$3 \mathrm{Kirsch}$ WM, Carlsson E, Hartmann AF Jr. A case of anomalous drainage of the superior vena cava into the left atrium. $\mathcal{I}$ Thorac Cardiovasc Surg 1961;41:550-6.

4 Vasquez-Perez J, Frontera-Izquierdo P. Anomalous drainage of the right superior vena cava into the left atrium as an isolated anomaly. Rare case report. Am Heart $\mathcal{f}$ 1979;97:89-91

5 Mornex JF, Brune J, Termet H, Bruyere B, Zhang HF. Une cause exceptionnelle d'hypoxie: l'abouchement de la veine cave supérieure droite dans l'oreillette gauche. Correction chirurgicale. Rev Fr Mal Respir 1983;11:149-55.

(Accepted 7 fuly 1986)

Hôpital B, University of Lille, 59037 Lille Cédex, France

D LEYS, MD, assistant in neurology

J MANOUVRIER, MD, assistant in cardiology

T DUPARD, $M D$, resident physician in neurosurgery

P KASSIOTIS, MD, assistant in neurology

C REY, MD, assistant in paediatric cardiology

P MARACHE, MD, associate professor in radiology

G DUCLOUX, MD, professor in cardiology

H PETIT, MD, professor in neurology

Correspondence to: Dr Leys.

\section{Munchausen's syndrome by proxy: a warning for health professionals}

False illness, or Munchausen's syndrome by proxy, has become increasingly recognised as a bizarre form of child abuse. ${ }^{1-3}$

An open warning of further injuries to come if no measures are taken to protect the child may be a presentation of child abuse, with bruises and injuries to the mouth being presented without any explanation. ${ }^{4}$ If child abuse is not considered then the child may suffer more serious injuries.

We describe a child presenting with such symptoms, which ultimately proved to be factitious.

\section{Case report}

A girl aged 4 months was brought in by her mother, who complained of bleeding from the child's mouth and blood in the stools. She was the mother's first child and had been conceived when the mother was 15 .

On admission the baby looked well with no cutaneous stigmata or evidence of bruising in the skin. Careful examination of the mouth showed no evidence of injury or haemangioma and subsequent examination under anaesthesia confirmed this. All laboratory investigations yielded normal results.

During the admission the child was shown to medical and nursing staff by the mother with blood apparently coming from the mouth. The mother lived on the 